\title{
La perspectiva antropológica en Michel Foucault y Ludwing Binswanger. Existencia, imaginación y facticidad
}

\section{Antropological perspective in Michel Foucault and Ludwing Binswanger. Existence, imagination and facticity}

\author{
MATIAS ABEIJON \\ Universidad de Buenos Aires (Argentina)
}

recibido: 04.01.2019

aceptado: 05.03.2019

\section{RESUMEN}

$\mathrm{El}$ presente trabajo tiene como objetivo investigar el fundamento existencialista de la introducción escrita por Michel Foucault a «Traum und Existenz» de Ludwing Binswanger. Sostenemos que Foucault, partiendo de la antropología binswangeriana, desarrolla el esbozo de una antropología de la imaginación. Esta antropología se centra en una serie de conceptos: sueño, existencia, libertad, imagen e imaginación. Sin embargo, a diferencia del Daseinsanalyse, Foucault pone el acento en la facticidad y en la expresión histórica de la libertad. En este punto se plantea una diferencia importante entre ambos autores: mientras que Binswanger pone el acento en una noción de individuo que supedita su existencia individual a un ideal de totalidad comunitaria, Foucault destaca la necesidad de dirigir la dimensión fundante de la libertad hacia sus formas de expresión concretas.

PALABRAS CLAVE

FOUCAULT; BINSWANGER; EXISTENCIA; FACTICIDAD; PSIQUIATRÍA

\section{ABSTRACT}

The purpose of this article is to investigate the existential foundation in Foucault's introduction to Binswanger's «Traum und Existenz». It will argued that Foucault develops the sketch of an anthropology oh the imagination that supported in Binswanger's anthropology. The analysis focuses mainly on the concepts of dream, existence, freedom, image and imagination. Unlike the Daseinsanalyse, Foucault emphasizes the facticity and the historical expression of freedom. Whe-

Claridades. Revista de filosofía 11 (2019), pp. 79-106

ISSN: 1889-6855 ISSN-e: 1989-3787 Dl.: PM 1131-2009

Asociación para la promoción de la Filosofía y la Cultura (FICUM) 
reas Binswanger supports a notion of subjetc who subordinates the individual existence to the ideal one of community totality, Foucault emphasizes concrete expression of the freedom.

\section{KEYWORDS \\ FOUCAULT; BINSWANGER; EXISTENCE; FACTICITY; PSYCHIATRY}

\section{INTRODUCCIÓN}

El PRESENTE TRABAjO analiza los fundamentos fenomenológicos-existencialistas y la influencia de la antropología biswangeriana en el primer texto publicado por Foucault: la introducción al artículo «Traum und Existenz» de Binswanger (a partir de ahora: IB). La introducción de Foucault está dominada por los temas fenomenológicos franceses de la de década del cincuenta: el concepto heideggeriano del mundo y la existencia, la investigación merleau-pontyana de la experiencia y la expresión, la preocupación sartreana de la constitución humana del mundo y el papel de la imagen, la distinción husserliana entre la indicación y la significación. Esta mixtura de temáticas propias de la época, y especialmente la postura existencialista explícita que Foucault toma en la IB (y que, como trataremos de demostrar, se fundamenta en una figura del sujeto de cuño existencialista), ha llevado a algunos comentadores a considerar este texto como parte de una prehistoria juvenil del «Foucault real» (es decir, el Foucault posterior a 1961) que carece de cualquier importancia filosófica (Sheridan, 1980). Además, en un tardío texto de 1984, Foucault afirmará lo siguiente respecto a ese primer texto:

«Por dos razones, que no son independientes entre sí, este proyecto me parece insatisfactorio: su insuficiencia teórica en la elaboración de la noción de experiencia y la ambigüedad de su relación con una práctica psiquiátrica que al mismo tiempo ignora y presupone. Podemos enmarcar la primera dificultad en la referencia a una teoría general del ser humano; y tratar el segundo problema por el recurso repetido del 'contexto económico y social'; o podemos aceptar el dilema dominante de una antropología filosófica y de una historia social. Pero me pregunto si no hay otra posibilidad, además de esas dos alternativas, de pensar históricamente las formas de experiencia» (Foucault, 1994d: 579).

Este preconcepto generalmente ha derivado en análisis poco rigurosos de la IB. ${ }^{1}$ A excepción de los notorios trabajo de Basso (2012; 2015; 2016a;

1 Mencionamos sólo dos casos representativos de estos tratamientos parciales. Por una parte, Miller, en su biografía sobre Foucault, concluye lo siguiente respecto al interés del 
2016b), pocos son los autores que la han analizado de manera íntegra (Chebili, 2005; Gros, 2000; Moreno Pestaña, 2006; Revel, 1992; Smyth, 2011). Sí existen trabajos más numerosos sobre la relación entre la obra de Foucault y la fenomenología (Babich, 2009; Castro, 1995; Dreyfus \& Rabinow, 2001; Lebrun, 1989; Micieli, 2003; Milchman \& Rosenberg, 2003; Rayner, 2010; Visker, 1999; Zougrana, 1998), pero estos se centran en el tratamiento de la misma en Les motes et les choses (1966), o bien en el análisis de la presencia de la figura de Heidegger en la conceptualización foucaulteana de la historia y del poder.

Sostendremos, pues, las siguientes hipótesis: 1) El análisis de Foucault se fundamenta en las figuras de la existencia auténtica e inauténtica, y de la libertad. 2) Si bien la IB retoma la antropología existencial planteada por Binswanger y dirige su análisis hacia el fundamento ontológico de dicha antropología, el bosquejo de una antropología de la imaginación planteado por Foucault pone el acento en la facticidad y lo concreto del hombre, tratando de superar la postura metafísica del Daseinsanalyse binswangeriano.

\section{LA ANTROPOLOGÍA BINSWANGERIANA}

Jacqueline Verdeaux es la responsable del encuentro entre Foucault y Binswanger. Esta mujer jugará un papel primordial en los años de formación del filósofo francés. En 1954, André Ombredane, un antiguo alumno de Georges Dumas, acababa de traducir un libro sobre el psicodiagnósti-

filósofo francés por Binswanger: «Es bastante evidente que Foucault halló en Binswanger un guía inusualmente bien dispuesto a comprender una preocupación con la muerte. (...) Binswanger no sólo describía el suicidio con insólita tolerancia; también proponía medios constructivos de reconocer y descifrar, en términos nietzscheanos, 'lo que uno es» (Miller, 1995: 104). Dejando de lado las insinuaciones amarillistas de Miller respecto a la sexualidad de Foucault y a sus intentos de suicidio (abundantes en su libro), la IB se reduce a la biografía del autor. Por otra parte, el trabajo de Morey es representativo de otra forma de tratamiento de la IB: analizarla a partir de los desarrollos posteriores de Foucault, excluyendo su contexto original de producción. En el caso de Morey, la IB es leída a través de la temática de la exclusión de Histoire de la folie à l'áge classique (1961): «En otro texto publicado en el mismo año 1954, un extenso prólogo a la obra de L. Binswanger, Traum und Existenz, Foucault subraya que las formas de lo Otro que Europa ha rechazado en la partición que la constituye, no siempre han sido excluidas, no son excluidas por doquier. Los sueños, la locura, sólo modernamente han accedido al estatuto de objeto de conocimiento, y han accedido precisamente a partir del momento en que han sido excluidas, es un mismo movimiento el que los objetiva y los excluye» (Morey, 1983: 53). 
co, y le pide a Jacqueline Verdeaux que se encargue de someter su traducción a la corrección de Roland Kuhn. Ombredane, además, le prestó un libro de Kuhn titulado La Phénoménologie du masque. Jacqueline lee el libro y parte para Turgovia, a Münsterlingen. Muestra a Kuhn la traducción de Ombredane, pero también le ofrece traducir el libro mencionado. Kuhn acepta, y sugiere traducir también un libro de Ludwig Binswanger. ${ }^{2}$ El propio Binswanger sugiere traducir un extenso artículo suyo: Traum und Existen\%: Jacqueline regresa a París y le pide ayuda a Foucault para realizar la traducción, pues la obra de Binswanger está plagada de términos filosóficos. Como afirma Descombes (1979), el campo intelectual francés de la época, y la enseñanza universitaria, giraba en torno a las tres $\mathrm{H}$ (Heidegger, Hegel y Husserl); Foucault estudiaba especialmente la fenomenología husserliana y merleaupontiana, y no ignoraba la psiquiatría existencial. Según su propio testimonio:

«La lectura de lo que ha sido definido como 'análisis existencial', o 'psiquiatría fenomenológica', sin duda tuvo importancia para mí: era un período en el cual trabajaba en los hospitales psiquiátricos y buscaba algo distinto de los tradicionales esquemas de interpretación de la mirada médica. Esas soberbias descripciones de la locura, como experiencias fundamentales, únicas, no superponibles a otras, fueron determinantes» (Foucault, 2010: 76-77).

Por otra parte, en la lista que Foucault entrega a las autoridades de la universidad de Lille para rendir cuentas de sus actividades llevadas a cabo durante los años 1952-1953 figura: «Psychiatrie et analyse existentielle (tesis complementaria). Obra terminada (En prensa. Desclée)» (Eribon, 1990: 96). ${ }^{3}$ Entre las lecciones impartidas en Lille, dictadas entre 1952 y 1953 , además, figuran dos cursos de orientación fenomenológica: «Binswanger y la fenomenología» y «Fenomenología y psicología» (Sabot, 2015). «Rêve et

2 Esta no será la primera traducción de un texto de Binswanger al francés. La primera traducción al francés de uno de sus artículos fue «La conception de l'homme, chez Freud, à la lumière de l'anthropologie philosophique», que se publica en 1938 en la revista L'Évolution psychiatrique. Fue traducida por el asistente de Minkowski, Hans Pollnow, un psiquiatra y filósofo judío que huyó de la Alemania nazi en 1933 y que dicta cursos sobre psicología de la infancia en el Instituto de historia de las ciencias de la Sorbonne. Durante sus estudios de medicina y filosofía en Munich y en Heidelberg, Pollnow siguió los cursos de Karl Jaspers, a quien también tradujo en los años treinta (Basso, 2015).

3 Naturalmente, dicha obra nunca se publicó, y actualmente no se han encontrado registros de dicho trabajo; la tesis complementaria esperará hasta 1961, y versará sobre la Antropología de Kant. 
existence» se publica en 1954, en las Editions Desclée de Brouwer, en la colección «Textes et études anthropologiques»"

El artículo de Binsawnger «Traum und Existenz» se publica en 1930. Si bien el desarrollo sistemático de su doctrina del Daseinsanalyse, se lleva a cabo a partir de la década del cuarenta, especialmente en su obra de 1942 Grundformen und Erkenntnis menschlichen Daseins, suele considerarse a este artículo como una de las primeras muestras del mismo (Spiegelberg, 1972; Ellenberger, 1958). Por análisis existencial, Binswanger entiende una investigación científica y antropológica, dirigida al ser humano. Su nombre y su fundamento filosófico proceden de la analítica de la existencia de Heidegger: «El mérito, aun no bastante valorado de este último, consiste en haber dado a la existencia una estructura fundamental y haberla presentado en sus derivaciones esenciales, a saber, la estructura del 'seren-el-mundo» (Binswanger, 1973a: 166). La mención de ser-en-el-mundo tiene, en Heidegger, el carácter de una tesis ontológica, esto es, de un enunciado sobre un comportamiento esencial de la existencia en general. ${ }^{5}$ El análisis existencial de Binswanger es, sin embargo, una ciencia experimental, en el sentido de que sigue el método y el ideal de exactitud de las ciencias experimentales fenomenológicas. La analítica existencial objeta la

4 Henri Ey es otra figura importante en la historia de la recepción de Binswanger en Francia. En 1948, crea con la editorial Desclée de Brouwer la colección «Bibliothéque neuro-psychiatrique de langue française», en la que se publicarán las obras de psiquiatras y neurólogos que, en esa época, contribuye a introducir en Francia la psicopatología fenomenológica germanoparlante: Eugène Minkowski, Roland Kuhn, Ludwing Binswanger, Françoise Minkowksa, Frederik Jacobus, Johannes Buytendijk, etc. En esta colección se publicará también la traducción de Michel Foucault y de Daniel Rocher de la obra principal del neurólogo alemán Viktor von Weizsäcker, Le cycle de la structure (1958) con prefacio de Henri Ey. El también será el primero en reseñar «Le rêve et l'existence» en un artículo publicado en 1956 en L'Evolution psychiatrique» (Basso, 2013).

5 En un artículo de 1946, «Ueber die daseinsanalytisch Forschungsrichtung in der Psychiatrie» (De la dirección analítico-existencial de la investigación en psiquiatría), Binswanger resalta la importancia del Dasein en la analítica existencial: «el conocimiento de la estructura o constitución fundamental de la existencia nos proporciona una línea directriz sistemática para la exploración práctica analítica existencial. Ahora sabemos qué tenemos que observar en la exploración de una psicosis, según qué puntos de vista tenemos que proceder, sabemos que hemos de tener bien claro de qué clase es la espacialidad y la temporalidad, la iluminación y colorido, la consistencia o materialidad y la movilidad de esbozo del mundo, en el cual se proyecta la respectiva forma de existencia o figura individual existencial» (Binswanger, 1973a: 176). 
persistencia del concepto de causalidad legado por las ciencias naturales a la psicología. Binswanger niega que exista algo detrás de los fenómenos que los explique o que cause su aparición, y descarta las explicaciones de la existencia del hombre en función de un sí mismo, un inconsciente, una energía psíquica o física, o fuerzas tales como los instintos, las ondas cerebrales, los impulsos y los arquetipos (Hall \& Gardner, 1977). Siguiendo la metodología fenomenológica, para Binswanger la comprensión debe realizarse sin ninguna hipótesis o prejuicio previos. ${ }^{6} \mathrm{~A}$ partir de este método, la analítica existencial se propone analizar el ser-en-el-mundo o Dasein, la existencia del hombre, en sus formas antropológicas y en sus dimensiones fundamentales.

Retomando «Traum und Existenz», Binswanger analiza las dimensiones del ascenso y la caída. Estos movimientos se hallan en las bases más profundas de la existencia, allí donde la forma vital anímica y el contenido vital anímico aún no se encuentran separados. La segmentación del humano en alguna de sus esferas, por ejemplo la forma corporal, sería lo que caracteriza a la perspectiva de la psiquiatría:

«Sólo aquel que no observa al hombre en su totalidad, sino en uno de sus aspectos, como lo hace el biólogo -porque ser hombre es más que vivir-, dirá que aquella dirección de arriba hacia abajo, la caída, está puramente fundada en la estructura viviente del organismo, pues por un choque repentino se produce una pérdida de tensión o de tono en nuestra musculatura estriada, por lo cual perdemos a medias o del todo el sentido y caemos, y que de ese cuadro puramente corpóreo se nutre el lenguaje. Según este crite-

$6 \mathrm{Si}$ bien hay toda una serie de aspectos peculiares que hacen que la fenomenología se vuelva atractiva para la psicopatología y la psiquiatría, Waldenfels destaca el siguiente: «En la medida en que Husserl comprende la locura como 'modificación intencional' de una comprensión normal del mundo, le atribuye un sentido, no distinto al de la vivencia normal que no es simplemente normal sino que se normaliza de cualquier manera. Como sostienen unánimemente Binswanger, Minkowski, Goldstein y Canguilhem, la enfermedad, incluso la así llamada enfermedad mental, no constituye un déficit puro, un puro desorden, sino un orden distinto en el cual se encarna una norma propia. En otras palabras: el enfermo tiene un mundo extraño y habla un lenguaje extraño. Con la duda en cuanto a una razón omniabarcadora, resulta cuestionable incluso el supuesto husserliano de una forma primaria inequívoca en la que se basen todas las modificaciones; las fronteras entre razón y locura dejan de ser rígidas cuando hay una 'historia de la locura' (Foucault). Ronald Laing, uno de los nombres de la antipsiquiatría, en su escrito The Devided Self (1959) y en sus estudios interpersonales The Self and the Others (1961) evoca no solamente a Binswanger sino se remonta también al interminable juego de batalla y espejos intersubjetivo de Sartre» (Waldenfels, 1997: 108). 
rio, el caer de todos los cielos sería en realidad una mera transferencia de un estado de cosas de la esfera de lo corpóreo al ámbito de lo anímico. (...) Sin embargo, el hundirse o el caer representa una orientación general de la significación de arriba y abajo que, según el 'existencial ontológico', acaso por el determinado alejamiento en el espacio, por la disposición anímica de ‘ser arrojado’ o la interpretación de la comprensión, contiene una noción existencial especial para nuestra existencia» (Binswanger, 1973b: 68).

El caer y el elevarse de nuestra existencia entraña todas las concepciones religiosas, míticas y poéticas de la ascensión del alma al cielo y del peso terrenal del cuerpo. En estas dimensiones de la existencia se sitúan la poesía, el mito y el sueño, que, según Binswanger, han estado más cerca de la respuesta respecto al misterio del sueño, que la ciencia y la filosofía:

«La pregunta acerca del 'quien' de nuestra existencia no se contesta por la figura individual percibida por los sentidos, que es insignificante, sino por medio de un factor que puede servir de sujeto a determinado factor de la estructura que aquí representa la ascensión o la caída, a pesar de que en su configuración sensorial sea para nosotros un sujeto extraño, exterior. A pesar de ello sigo siendo yo el sujeto original de aquello que se eleva y cae. En estas inteligencias verdaderamente ontológicas reposa el valor verdadero y gran parte de la acción de las descripciones del sujeto de la existencia en el mito, la religión y la poesía» (Binswanger, 1973b: 70).

El sueño se rige por la personificación dramática, su modo principal de expresión: «yo no caigo de las nubes, como un ser aislado y solitario en mi dolor, sino que es mi dolor mismo el que cae como una segunda persona dramática» (Binswanger, 1973b: 71). Se suele relacionar los sueños de vuelos y caídas con estados corpóreos, o con disposiciones de ánimo eróticas o deseos puramente sexuales. Si bien ambas cosas son posibles, para Binswanger se trata del descubrimiento de una estructura apriorística para la cual tanto la explicación de la excitación corpórea como el esquema corpóreo y la tematización erótico-sexual son satisfacciones especiales y secundarias. Para la interpretación del sueño no importa si el drama que se desarrolla en el silencio del alma trascurre en el papel de la persona misma del soñante o en uno, dos o más papeles secundarios junto a esa persona o sólo en tales papeles secundarios. El tema que fija la existencia mientras duerme, el contenido del drama, es lo central; el reparto de personajes es, por el contrario, lo casual y accesorio.

Las imágenes cobran importancia en la perspectiva binswangeriana del sueño; en ellas se representan los deseos y temores del hombre, y su presencia es índice de salud espiritual, pues las imágenes dramáticas expresan las disposiciones anímicas. La expresión del sueño indica, a grandes ras- 
gos, que las esferas de lo interior y lo exterior no se encuentran escindidas en esta perspectiva antropológica. Sin embargo, el hombre actual separa su mundo interior y su mundo exterior, pues está dominado por fuerzas no espirituales, económicas y técnicas. El hombre de la antigüedad, por el contrario, no conoce ni en la vigilia ni en el sueño esa división:

«Vive en un cosmos al cual ni siquiera sus decisiones más íntimas, más concretas, en el ensueño como en la vigilia, pueden sustraerse, pues aquello que vivimos con motivos en el momento de la decisión, son, para los creyentes, los dioses. En ellos, no en el espíritu infinito, está el fondo y la razón de todo lo substancial que ocurre en el hombre. No es que queramos adoptar hoy sin más las acabadas formas del helenismo; ello sería para el psicólogo un programa de poco alcance, un propósito de maestro de escuela, pero podemos advertir, con el humanismo moderno, que la historia espiritual de los griegos es la construcción de un mundo de formas, en el que se despliegan continuamente las leyes naturales del hombre, y que, en la profundización en ese mundo de formas se trata nada menos que de la autocomprensión y autoconstrucción del hombre espiritual en la estructura básica de su esencia» (Binswanger, 1973b: 77-78).

Para los antiguos griegos, los límites entre el sueño y el acontecimiento del mundo exterior son confusos; también lo son los límites entre la esfera de las vivencias interiores, la de los acontecimientos exteriores y la esfera cultural. Lo que conmueve al hombre griego, según Binswanger, es que el sujeto de la imagen onírica, el sujeto del acontecer cósmico y el sujeto de la manifestación cultural son uno solo. La imagen onírica, el acontecer externo y el significado cultural forman una indivisible unidad: «¿Cómo puede hablarse aún de un sujeto individual? ¿Y quién habrá de decidir si hay que buscar aquí la verdad en lo interno de la subjetividad o en lo externo de la objetividad? Todo interior es aquí exterior, como todo exterior es también interior» (Binswanger, 1973b: 79). No puede pensarse en una vida cadente y ascendente en el sentido del decurso vital del individuo aislado, sino más bien en aquello que en la felicidad sube, y en la desgracia, cae. El individuo, la raza, el destino y la divinidad están entretejidos en un único espacio expresados en la estructura ontológica de la ascensión y la caída. En lugar de nuestro adentro y fuera, oposición neoplatónica y cristiana, aparece en los antiguos griegos la contraposición del día a la noche, de la oscuridad a la luz y de la tierra al sol. Los ensueños pertenecen al dominio de la noche y de la tierra.

Sin embargo, entre los griegos, al lado de esta religiosa y unitaria concepción del mundo también había lugar para la teoría científica y empírica, expresada en una interpretación filosófico-metafísica del mundo enten- 
dido como una coherencia del acontecer desde lo más universal hasta lo más individual. Para Binswanger, esta concepción unitaria se encuentra encarnada en la figura de Heráclito:

«Ya en la primera parte de nuestro trabajo hemos examinado la individualidad, es decir, el soñante aislado en orden a lo general. (...) Lo universal, que allí nos ocupaba, el contenido de la imagen supraindividual, no es realizada por cada individuo, sino que cada individuo lo tiene en el ensueño, sólo él lo ve y sólo él es deleitado o torturado por él. Sus imágenes, sus sentimientos y su estado de ánimo le pertenecen exclusivamente, vive totalmente y sólo en su mundo propio, y sólo eso se llama, psicológicamente hablando, soñar, ya durmamos o estemos despiertos fisiológicamente. Esto ya lo ha considerado Heráclito decisivo para la caracterización del soñante y su diferenciación de la vida anímica en vigilia» (Binswanger, 1973b: 83).

La concepción unitaria heraclítea se expresa en su noción de mundo, cosmos; ésta no refiere al mundo objetivo, sino al estado subjetivo de la unión y de la dispersión. Para Heráclito, lo determinante de esta unión y dispersión es el $\log o s^{7}{ }^{7}$ A todas sus acepciones, son común el entendimiento o el pensar reflexivo, «lo común», y hay, por tanto, algo en lo que todos podrían encontrarse o entenderse en algo común, en el propio logos. Todos participamos de este logos, sea despiertos o soñando. No obstante, la mayoría vive como si tuviesen un entendimiento propio o un pensar propio, individual, separado de lo común. Esto último es un ensueño deliberado, una ilusión. Por lo tanto, a los soñantes deliberados les está oculto lo que hacen mientras están despiertos, del mismo modo que olvidan lo que hicieron mientras dormían. Sólo viviendo en la conciencia de esta interdependencia, estamos despiertos. Mientras participamos del conocimiento del entendimiento divino estamos en la verdad; pero en la medida en que tengamos algo especial e individual, estamos en el error.

Finalmente, Binswanger retoma la línea del tratamiento terapéutico, y traza un paralelo entre ella y la concepción unitaria (antropológica) del sueño:

«en todo tratamiento anímico serio, y en particular en el psicoanálisis, se presentan momentos en que el hombre tiene que decidir si quiere conservar su opinión particular, su teatro privado, su altivez, orgullo y obstinación, o si, por medio del

\footnotetext{
7 Binswanger traduce logos de múltiples maneras: «palabra» o «habla», «pensamiento», «enseñanza», «necesidad de pensar» y «relación razonable y normativa» (Binswanger, 1973b: 85). En un artículo de 1935, «Heraklites Auffassung des Menschen» (El concepto de hombre según Heráclito), Binswanger sintetiza la perspectiva heraclítea del logos y lo común. Véase: Binswanger, 1973c.
} 
médico, como intermediario sapiente entre el mundo propio y el mundo común, entre el engaño y la verdad, quiere despertar de su sueño y tomar parte en la vida de la generalidad. (...) Con el despertar del sentido de lo infinito, en contraposición a la restricción a lo particular, el individuo no se ve privado de sus imágenes, sentimientos, deseos ni esperanzas; éstos sólo serán despojados del torturante desasosiego, de la intranquilidad y desesperación, de la vida cadente, que se hunde, que desciende, aunque no llevados a la placidez total, eso sería la muerte, pero sí a una vida ascendente, fluctuante y tranquila» (Binswanger, 1973b: 84-85).

Al soñar, en el yo y en el para mí se pone de manifiesto otra vez el individuo, pero no como aquel que sueña, pues este individuo es una indicación puramente formal sin substancia sometida al juego de la vida cadente y ascendente. El individuo dejará de ser sólo un 'él mismo' en el decurso de los acontecimientos cuando se decida a llevar continuidad o consecuencia en la vida que se eleva o que cae. El fundamento del sueño, entonces, es la existencia. El tránsito a la vigilia es paulatino y, por lo tanto, el comienzo del sueño y el final de la vigilia están en lo infinito: «Nosotros no sabemos dónde empiezan vida y ensueño, por eso en el transcurso de nuestra vida se nos recuerda continuamente que es superior a las fuerzas humanas 'el ser individuo' en el más alto sentido» (Binswanger, 1973b: 88). Finalmente, la estructura ontológica del ascenso y la caída pareciera no sólo estar anclada y fundada en la existencia, sino tener pretensiones universales. El eje vertical expresa la existencia humana en el sueño en una inmediatez absoluta, y su origen pareciera remitir a lo eterno, descubierto por el genio griego y olvidado por el hombre moderno. ${ }^{8}$

\section{SUEÑO Y EXISTENCIA EN IB}

En una carta que Foucault envía a Binswanger el 27 de abril de 1954, expresa los objetivos de su $I B$ de la siguiente forma:

«Por el momento sólo tengo dos preocupaciones: mostrar la importancia sig-

nificativa del sueño para el análisis existencial, y mostrar cómo su concepción

8 Seitter sintetiza este punto afirmando que esta dimensión vertical refiere, en última instancia, a una «metaforología» que expresa las cualidades y movimientos del alma: «Pero el texto de Binswanger no es la aplicación de una filosofía. Parte de una metaforología donde se trata de expresiones como 'caer', 'volar', 'planear' que provienen de la esfera sensorial espacial y conciernen a las cualidades y movimientos del alma. En el lenguaje cotidiano y en el lenguaje poético esas expresiones tienen un empleo metafórico que se afirma en los sueños, en los cuales las situaciones son vividas como otras tantas modalidades de existencia» (Seitter, 1990: 141). 
del sueño implica una renovación completa del análisis de la imaginación. Mostrando el grado en que 'Traum und Existenz' refuta la teoría de los sueños y la teoría de la imaginación y haciendo hincapié en las implicaciones antropológicas de su análisis, espero haber puesto su pensamiento al alcance de los lectores franceses, tan apegados a las cosas antiguas, sin haber, sin embargo, disminuido su importancia. Es en este espíritu que me he permitido esbozar una antropología de la imaginación que parecía implícito en el texto» (Basso, 2015: 183).

En ella se destaca el recorrido general del texto de Foucault: el pasaje de la perspectiva antropológica existencial al esbozo de una antropología de la imaginación. En este recorrido, a través de una amplia serie de críticas (a la psiquiatría de la época, al psicoanálisis, a la fenomenología husserliana y a la concepción sartreana y bachelardiana de la imagen), situará el fundamento de la antropología binswangeriana en el marco de su fundamento existencial: la existencia auténtica (ligada a la figura fundante de la libertad) e inauténtica (la caída en la patología mental).

Foucault comienza por afirmar que la forma de análisis fundamental en relación a todo conocimiento concreto, objetivo y experimental, es la que toma por objeto al hombre, el ser-hombre, el «Menschsein» (Foucault, 1994a: 66). Esta forma de análisis es la antropología existencial desarrollada por Binswanger, proyecto que se sitúa en oposición a las formas de positivismo psicológico que agotan el contenido significativo del hombre con el «concepto reductor de homo natura y la reubica, a la vez, en el contexto de una reflexión ontológica que tiene como tema mayor la presencia del ser, la existencia, el Dasein» (Ibíd.). Según Foucault, el Menschsein es el contenido efectivo y concreto de lo que la ontología analiza como la estructura trascendental del Dasein, de la presencia en el mundo. ${ }^{9}$ En definitiva, la

9 Si bien es mencionado explícitamente pocas veces, la IB presenta una evidente terminología heideggeriana propia de la obra de Binswanger. En lo referido a la recepción de Heidegger en Francia, al momento de la escritura de la IB existen dos momentos: uno previo a la década del cuarenta, donde se lee a Heidegger desde el mismo punto de vista que Husserl y Jaspers. Para esta generación filosófica francesa, Heidegger servía al combate contra el bergonismo instaurado a partir de la década del treinta. Se trataba de poner en el centro de la filosofía el desgarramiento del hombre, sus fisuras y sus carencias, así como lo patético de su existencia y de su ser-para-la-muerte. Un segundo momento de la recepción francesa de Heidegger remite a su confrontación con el existencialismo de Sartre, a partir de la «Carta sobre el humanismo» (1946). Este texto abrió la puerta para un nuevo entendimiento de Heidegger en Francia que se opuso al existencialismo sartreano. En la persona de Jean Beaufret, varios jóvenes intelectuales universitarios franceses plantearon una relación directa con Heidegger y encontraron una alternativa a lo que ahora se veía 
antropología existencial se opone a la explicación naturalista del hombre:

«Su oposición original a una ciencia de los hechos humanos al estilo del conocimiento positivo, del análisis experimental y de la reflexión naturalista no remite pues la antropología a una forma a priori de especulación filosófica. El tema de su investigación es el 'hecho' humano, si se entiende por ello no tal sector objetivo de un universo natural, sino el contenido real de una existencia que se vive y se siente, se reconoce o se pierde en un mundo que es a la vez plenitud de su proyecto y el 'elemento' de su situación. La antropología puede designarse como 'ciencia de los hechos' desde el momento en que desarrolla rigurosamente el contenido existencial de la presencia en el mundo» (Ibíd.).

La temática central del artículo de 1930 no sería, según el filósofo francés, el sueño y la existencia, sino la existencia tal como aparece ella misma y tal como puede descifrársela en el sueño. El privilegio significativo concedido por Binswanger a lo onírico tendría una doble importancia. Por un lado, define la orientación concreta del análisis hacia las formas fundamentales de la existencia:

«el análisis del sueño no acaba en el nivel de una hermenéutica de los signos; sino que, a partir de una interpretación exterior que aún es del orden del desciframiento, puede, sin tener que esconderse en una filosofía, alcanzar la comprensión de las estructuras existenciales. El sentido del sueño se despliega de manera continua de la cifra de la apariencia a las modalidades de la existencia» (Foucault, 1994a: 68).

Por otro lado, el privilegio de la experiencia onírica implica una antropología de la imaginación, no desarrollada con detenimiento por Binswanger en «Traum und Existenz», y que encierra una nueva definición de las relaciones del sentido y del símbolo, de la imagen y la expresión.

Foucault destaca la coincidencia de las publicaciones de las Logische Untersuchungen de Husserl (publicadas en 1899) y de la Traumdeutung de Freud (1900). En ambas obras se trabaja la relación entre el sentido, la expresión y la imagen. El texto de Freud es interrogado a partir de las relaciones que allí se establecen entre significación e imagen en el sueño. El fundador del psicoanálisis convierte las imágenes del sueño en manifestación del deseo.

como un existencialismo moralizante. Para Sartre, el hombre es un ente lanzado a la contingencia de una existencia dada, mientras que para el «verdadero» Heidegger, repensado por Beaufret, el hombre es el alli del Ser, lo que le permite al Ser revelarse, des-velarse. De allí la traducción de Dasein por Estar-alli, en lugar del término realidad bumana adoptado anteriormente por los intelectuales franceses, incluido Sartre (Kleinberg, 2005). Para un desarrollo más extenso de la recepción de Heidegger en Francia, véase: Geraulanos, 2010; Pettigrew \& Raffoul, 2008; Rockmore, 1995. Especialmente, véase: Janicaud, 2001. 
Si bien el sueño no ofrece en imágenes la transparencia del deseo del individuo que sueña, se manifiesta en forma velada a través del conflicto entre deseos: el material onírico surge de un compromiso entre ellos. Foucault considera que, de esta forma, Freud permanece en la dimensión semántica del sueño sin ser capaz de analizar sus dimensiones morfológicas y sintácticas. Es decir, el psicoanálisis ignora la estructura del imaginario en el sueño, concentrándose en las dimensiones significativas de las imágenes. De ese modo, se centra en lo anecdótico e ignora la estructura del lenguaje que da cuerpo al sueño. A su vez, Husserl intentó diferenciar entre índice y significación, y con ello precisó la semántica (amenazada por un psicologismo del deseo subjetivo) elaborada por Freud. De esta manera, el significado deja de reducirse a un sentido que le sería ajeno, y pasa a ser representante de una realidad exterior. El índice remite a una situación objetiva mientras que el signo reposa sobre una actividad significativa que debe reconstruirse desde el interior de ella misma. Esta primera diferenciación entre signo e índice se acompaña de una segunda: la existente entre significación e imagen. El acto significativo interpela la unidad ideal de un objeto del que pueden realizarse distintas predicaciones. Ese objeto ideal no puede reducirse a un contenido psicológico preciso. Una figura geométrica, por ejemplo, un triángulo, posee una esencia propia e independientemente de cada triángulo dibujado: esa esencia permanece como una referencia ideal sin la cual no cobran sentido las diferentes actualizaciones empíricas de la misma. Husserl presintió que no cabía reducir los símbolos a semejante unidad significativa ideal. El significante en el que se expresa en cada ocasión el objeto ideal contiene una densidad propia, e implica una intención expresiva específica. Pero, según Foucault, Husserl no supo ver que en ese mundo de significantes, lo imaginario queda reducido a la subjetividad que se expresa en él (Moreno Pestaña, 2006). ${ }^{10}$

10 Frederic Gros sintetiza la crítica de Foucault al psicoanálisis y a la fenomenología de la siguiente forma: «En su texto, Foucault objeta a la vez psicoanálisis y fenomenología onírica: el primero nos enseña a leer el sentido de un sueño, pero omite la instancia de donación subjetiva de ese sentido para retener únicamente el momento del código; la fenomenología husserliana, por su parte, dilucida con claridad en su pureza la actividad significante, pero renuncia a comprender cómo se realiza el sueño en estructuras objetivas de expresión que superan las posibilidades de un sujeto. Según Foucault, el sueño debe comprenderse, más acá de esta alternativa, en su dimensión de experiencia existencial, y no como texto significante a descifrar (psicoanálisis) o a constituir (fenomenología)» 
Volviendo a Freud, según Foucault el psicoanalista vienés no llegó a superar un postulado de la psicología del siglo XIX: que el sueño es una rapsodia de imágenes. Si el sueño fuera sólo eso, se agotaría mediante un análisis psicológico. Sin embargo, como hemos visto, el sueño no es una rapsodia de imágenes, sino una experiencia imaginaria que no se deja agotar por un análisis ni psicoanalítico ni fenomenológico. Binswanger recupera la idea de que el valor significativo del sueño ya no se mide según los análisis psicológicos que de él pueden hacerse: «La experiencia onírica, por el contrario, detenta un contenido tanto más rico cuanto se muestra irreductible a las determinaciones psicológicas en las que se intenta insertarlo» (Foucault, 1994a: 81). Foucault traza un recorrido que va desde la antigüedad hasta el romanticismo, destacando los textos cartesianos y postcartesianos, pasando por Spinoza y por los dramaturgos de la edad clásica francesa. Todas estas concepciones constituyen una doble polaridad en la filosofía imaginaria del sueño: la polaridad agua-fuego, y la polaridad luz-oscuridad. El sueño, como experiencia imaginaria, es un indicio antropológico de trascendencia:

«en esta trascendencia, le anuncia al hombre el mundo haciéndose él mismo mundo, y tomando las formas de la luz y del fuego, del agua y de la oscuridad. Lo que nos enseña la historia del sueño en su significación antropológica, es que es a la vez revelador del mundo en su trascendencia, y también modulación de este mundo en su sustancia, sobre el elemento de su materialidad» (Foucault, 1994a: 87). ${ }^{11}$

En esta medida, la experiencia onírica posee un contenido ético. No porque devele deseos inconfesables, sino porque restituye el movimiento de la libertad en su sentido auténtico, manifestando de qué manera se constituye como responsabilidad radical en el mundo o lo olvida y se abandona a la caída en la causalidad. Si el sueño es portador de las significaciones humanas más profundas, no es en la medida en que denuncia

(Gros, 2000: 21). Para un análisis más de detallado de la crítica foucaulteana a la fenomenología, véase: Kripper, 2013.

11 Foucault reconoce la raigambre heraclítea sostenida por Binswanger, respecto a la comunión del soñante con el mundo diurno: «En el origen de este tema del sueño como manifestación del alma en su interioridad, más bien encontraríamos el principio heracliteano: 'El hombre despierto vive en un mundo de conocimiento; pero aquel que duerme está girando hacia el mundo que le es propio'. A parte de en Traum und Existenz, Binswanger ha insistido varias veces sobre este principio, para captar toda su medida conceptual, y sacar a la luz su significado antropológico» (Foucault, 1994a: 91). Más adelante veremos que este principio se torna problemático para el propio Foucault. 
los mecanismos ocultos, sino en la medida en que pone al descubierto la libertad más originaria del hombre. El soñador encuentra en el sueño su mundo propio, reconociendo allí el rostro de su destino y el movimiento originario de su existencia. La significación antropológica del sueño, que Binswanger ha intentado captar en Traum und Existenr, contribuiría, según Foucault, al desarrollo de una antropología de la imaginación. Como ya mencionamos, el análisis antropológico de un sueño descubre más capas significativas que las que implica el método freudiano, y Binswanger capta mejor lo que puede ser considerado el sujeto del sueño: este sujeto no se describe como una de las significaciones posibles de uno de los personajes, sino como el fundamento de todas las significaciones eventuales del sueño; y tampoco es la reedición de una forma anterior o de una etapa arcaica de la personalidad, sino que se manifiesta como el devenir y la totalidad de la existencia.

En este movimiento del sueño hacia el porvenir aparecen, según Foucault, las significaciones fundamentales de la existencia que señalan las coordenadas fundamentales de su trayectoria. En la experiencia vivida, en su nivel originario, el espacio no se ofrece como la estructura geométrica de la simultaneidad. Antes de ser geométrico, o incluso geográfico, el espacio se presenta de entrada como un paisaje: «se da originariamente como la distancia de las plenitudes coloreadas o la de las lejanías perdidas en el horizonte, envuelto por la distancia que lo encierra, o incluso también es el espacio de las cosas que están ahí» (Foucault, 1994a: 101). Por oposición al espacio de la localización geográfica, el paisaje está paradójicamente cerrado por la abertura infinita; remite así al absoluto de una situación que recoge todas las potencias afectivas del hogar, de la tierra natal. En las dimensiones del espacio onírico encontramos, entonces, ciertas formas de la espacialidad que develan el sentido mismo de la existencia: la articulación del espacio próximo con el espacio lejano, la polaridad de lo claro y lo oscuro, y el eje vertical del espacio en su significación de existencia.

Este conjunto de oposiciones define las dimensiones esenciales de la existencia. ${ }^{12}$ Ellas forman las coordenadas primitivas del sueño como el espacio mítico de su cosmogonía. En los análisis de los sueños, estas

12 Para una síntesis de las categorías básicas a través de las cuales esta psiquiatría intentó reconstruir el mundo interior del enfermo (tiempo, espacio, causalidad, materialidad, etc.), véase: Ellenberger, 1967. 
coordenadas se componen y simbolizan unas con otras para constituir un universo. A su vez, cada acto de expresión debe comprenderse sobre el fondo de estas direcciones primeras. No se trata de remitir las estructuras de la expresión al determinismo inconsciente, sino de restituirlas a lo largo de esta línea según la cual se mueve la libertad humana. Foucault destaca tres estructuras fundamentales de expresión: la expresión épica, la expresión lírica, y la expresión trágica. Ésta última se encuentra situada sobre el eje vertical de la existencia; expresa el movimiento que es del orden de la ascensión y la caída, y el punto que lleva su marca privilegiada es aquel en el que se cumple el balanceo imperceptible de la subida que se detiene y oscila antes de caer. Como hemos visto, en «Traum und Existenz» Binswanger destaca esta dimensión. Foucault no lo desconoce, y afirma que ella es la más fundamental de las tres. En primer lugar, porque saca a la luz las estructuras de la temporalidad. La oposición horizontal, entre lo próximo y lo lejano, presenta el tiempo como una cronología de la progresión espacial; en esta cronología, el tiempo se desarrolla entre un punto de partida y un punto de llegada. En la oposición de lo claro y lo oscuro, el tiempo no es tampoco la temporalidad auténtica, pues se trata de un tiempo estacional, donde la ausencia es siempre promesa de regreso y la muerte implica resurrección. Por el contrario, con el movimiento de la ascensión y la caída, puede captarse la temporalidad en su sentido primitivo. Sobre esta dimensión vertical de la existencia pueden separarse las formas auténticas e inauténticas de la existencia: ${ }^{13}$

«Esta trascendencia de lo existente respecto de sí mismo en el movimiento de su temporalización, esa trascendencia que designa el eje vertical de lo imaginario puede ser vivida como un arrancarse de los fundamentos de la existencia misma; entonces cristalizarán todos los temas de la inmortalidad, de la supervivencia, del puro amor, de la comunicación inmediata de las consciencias; o puede ser vivida, por el contrario, como como caída inminente a partir de la cima peligrosa del presente; entonces lo imaginario se desplegará en un mundo fantástico de desastre; el universo no será ya más que el instante de su propia aniquilación: es el movimiento constitutivo de las experiencias delirantes de 'Fin del mundo'. El movimiento de trascendencia de la

13 En una nota al pie, Foucault destaca que, dentro de esta dimensión vertical, la expresión trágica deviene igual de fundamental en la expresión de las formas de la existencia: «En la medida en que la expresión trágica se sitúa sobre esta dirección vertical de la existencia, tiene un enraizamiento ontológico que le da un privilegio absoluto sobre los otros modos de expresión: éstos son más bien modulaciones antropológicas». (Foucault, 1994a: 109). 
temporalidad puede igualmente quedar cubierto y escondido por una pseudotrascendencia del espacio; entonces el eje vertical se reabsorbe enteramente en la trayectoria horizontal de la existencia; el porvenir se coloca en la lejanía del espacio; y contra la amenaza de muerte que lleva con él, la existencia se defiende mediante todos los ritos obsesivos que siembran de obstáculos mágicos los libres caminos del mundo. Podría describirse también la trascendencia que se asume únicamente en la discontinuidad del instante y que no se anuncia más que en la ruptura de uno consigo mismo: en este sentido fue como Binswanger describió la 'existencia maníaca» (Foucault, 1994a: 108).

Estas diferentes formas son las que, en última instancia, destacan las formas de la historicidad de la existencia, y las que devienen en fundamento de la antropología existencial e imaginaria planteada por Foucault. Cuando la existencia es vivida bajo el modo de la inautenticidad, no transcurre a la manera de la historia. Se deja absorber en la historia interior de su delirio o su duración se agota en el devenir de las cosas; se abandona a ese determinismo objetivo en el que se aliena su libertad originaria. La existencia, en la inautenticidad, se inscribe en el determinismo «objetivo» de la enfermedad. Foucault no nos habla específicamente de las características de la existencia auténtica, o bien de la estructura de lo auténtico, pero veremos que esboza una definición hacia el final de la IB.

Según Foucault, permaneciendo al nivel de las otras direcciones, nunca puede captarse la existencia más que en sus formas constituidas. Sólo la dimensión vertical permite captar la existencia en la dimensión originaria en la que se define el Dasein. De este modo, se abandona el nivel antropológico de la reflexión que analiza al hombre en tanto que hombre y en el interior de su mundo humano, para acceder a una reflexión ontológica que concierne al modo de ser de la existencia en tanto que presencia en el mundo. Así, se efectúa el paso de la antropología a la ontología: «Es la existencia misma la que, en la dirección fundamental de la imaginación, indica su propio fundamento ontológico» (Foucault, 1994a: 109).

\section{La Antropología de la imaginación. MÁs allá de Binswanger}

Foucault realiza un último movimiento: así como pasó de la antropología a la ontología, ahora avanza hacia el esbozo de una antropología de la imaginación. El filósofo francés comprende la imaginación como la dinámica misma del movimiento del sueño, el ascenso hacia una existencia que se configura originaria y libremente un mundo. Rebate explícitamente los análisis de Sartre en L'Imaginaire (1940) que plantean la imagen por 
referencia a lo real. A juicio de Foucault, la imaginación no asegura una irrealización del mundo sino la recuperación del movimiento mediante el cual la existencia se da un mundo. Por «imagen» (opuesta a la imaginación), Foucault entiende un sustituto coagulado de lo real que al parecer llega a interrumpir ese movimiento imaginario. En segundo lugar, Foucault critica al Bachelard de L'air et les songes (1943). Mientras que Bachelard considera que la imaginación culmina provisionalmente en la imagen, pero sin que la segunda acapare jamás a la primera, Foucault agota ónticamente el movimiento trascendente de la imaginación (Moreno-Pestaña, 2006). Las imágenes entonces, conciernen a una ontología de la imaginación que ningún contenido empírico podría agotar.

Finalmente, Foucault toma partido por la expresión poética. ${ }^{14}$ Ésta no encuentra su mayor dimensión en su capacidad de elaborar sustitutos metafóricos a la realidad; al contrario, su importancia reside allí donde la dispersión de las analogías se concentra y donde las metáforas, neutralizándose, devuelven su profundidad a lo inmediato. La imaginación poética no promueve y reúne imágenes, sino que las destruye: «El valor de una imaginación poética se mide por la potencia de destrucción interna de la imagen» (Foucault, 1994a: 116). En el curso del sueño, el movimiento de la imaginación se dirige hacia el momento primero de la existencia donde se cumple la constitución originaria del mundo. Ahora bien, si el sentido del sueño está siempre más allá de las imágenes que la vigilia retiene, no es porque éstas recubran potencias escondidas, sino porque la vigilia no puede llegar más que mediatamente hasta él. El análisis del sueño a partir de las imágenes que aporta la conciencia vigilante tiene por finalidad franquear esta distancia de la imagen a la imaginación, operar la reducción trascendental de lo imaginario. Según Foucault, Binswanger habría dado

14 Si bien la primacía del arte en los postulados teóricos de los intelectuales franceses de la época era un lugar común (una herencia intelectual y cultural del romanticismo alemán), para Binswanger también el arte, y especialmente el arte expresionista, ofrecía un poderoso ejemplo de la habilidad de moverse a través de la percepción a las sensaciones para acceder a la percepción de 'esencias'. El escritor, el pintor y el poeta tendrían la capacidad de captar las 'esencias', a través de la percepción pero superando sus límites sensoriales (Lanzoni, 2003). Inclusive, Marazia destaca que, en la perspectiva clínica de Binswanger, sólo los artistas e intelectuales podrían acceder a la posibilidad de la salvación, distinta de la cura terapéutica (Marazia, 2007). 
el primer paso hacia ello en «Traum und Existenz», en tanto esta reducción trascendental de lo imaginario implica el pasaje, antes mencionado, de una analítica antropológica del sueño a una analítica ontológica de la imaginación.

Un último punto de la argumentación foucaulteana retoma el problema de la expresión. La imagen ya no es imagen de algo, proyectada hacia una ausencia a la que reemplaza; está recogida en sí misma y se da como la plenitud de una presencia; no designa algo, se dirige a alguien. La imagen aparece como una modalidad de expresión, y cobra su sentido en un estilo, entendiendo por «estilo» el movimiento originario de la imaginación cuando toma el rostro del intercambio. La expresión, al estar dirigida a alguien, pasa a ser lenguaje, obra de arte y ética:

«Todos son problemas de estilo, todos los momentos históricos cuyo devenir objetivo es constitutivo de este mundo, de lo que el sueño nos muestra el momento originario y las significaciones rectoras para nuestra existencia. Y no porque el sueño sea la verdad de la historia, sino porque al hacer surgir lo que en la existencia hay de más irreductible a la historia muestra mejor el sentido que pueda tomar para una libertad que todavía no ha alcanzado, en una expresión objetiva, el momento de su universalidad. Por ello la primacía del sueño es absoluta para el conocimiento antropológico del hombre concreto; pero la superación de esta primacía es una tarea del porvenir para el hombre real (una tarea ética y una necesidad histórica)» (Foucault, 1994a: 118-119).

Estas últimas líneas oponen el sueño y la historia. Soñar era reproducir secretamente para sí el movimiento primitivo de la existencia que se daba un mundo y se ofrecía a él. Expresarse poéticamente será, al contrario, volver a investir en un mundo real las dimensiones fundadoras de la existencia, darlas a pensar a la comunidad de los hombres. Pareciera que el poeta es quien encarna, en última instancia, la existencia auténtica antes mencionada, en su tarea de constante destrucción de imágenes y develamiento del plano de la libertad. ${ }^{15}$ Una de las citas finales del texto,

15 May define del siguiente modo el estatuto de la libertad en la IB: «La imaginación humana es la posibilidad de constitución del mundo, trascendiendo la interioridad de la consciencia humana a través de un mundo que no se vuelve reductible ni a un polo subjetivo ni a elementos objetivos. Foucault llama a esa posibilidad, ‘libertad» (May, 2005: 291). Por otra parte, Agamben establece una relación entre la imaginación y el movimiento de la libertad de la $I B$, y los postulados sobre la arqueología de 1969: «El texto en el que Foucault ha descrito (o presentido) con mayor precisión las estrategias y los gestos de la arqueología es quizá su primer escrito publicado, el largo prefacio a Le Rêve et l'existence de Ludwing Binswanger. Si bien el término 'arqueología' obviamente está ausente, el 'movimiento de la libertad' que aquí se atribuye al sueño y a la imaginación comparte 
del poeta René Char, así lo expresa: «poesía y verdad, siendo, como ya sabemos, sinónimos» (Foucault, 1994a: 118). Las imágenes, en la poesía, no se dirigen a algo, sino a alguien, ingresando en el campo de la intersubjetividad. La función y la tarea del hombre, en el sentido de su existencia auténtica, es situarse en la siguiente paradoja: transformar un hecho fabuloso e irreductible a la historia (la libertad constitutiva de la existencia), en hecho histórico.

Como puede observarse, la IB va más allá de las pretensiones del artículo que introduce; a fin de cuentas, a la perspectiva antropológica existencial de Binswanger, sumada a su (explícita) ontología heideggeriana, Foucault le suma la necesidad de elaborar una antropología de la imaginación, que la $I B$ apenas bosquejaría, y a partir de la cual la libertad existencial podría traducirse en su dimensión histórica. El propio Binswanger señala una diferencia importante entre su perspectiva y la de Foucault. En una carta de Binswanger enviada al filósofo francés, en la que desarrolla algunas observaciones sobre el manuscrito de la $I B$, señala:

«El único punto en el que estoy en desacuerdo se encuentra en la página 2, y exactamente donde usted dice que el ser humano es el contenido real y efectivo de lo que la ontología llama facticidad. De hecho, estoy totalmente de acuerdo con Hans Kunz cuando dice que todos los existenciales del ser-en-el mundo también podrían ser considerados caracterizaciones del ser humano, lo que Heidegger denomina existencia, la decadencia, la decisión, y así sucesivamente» (Basso, 2015: 187-188).

con aquella significados y objetivos. Desde el comienzo, se desmiente decididamente la tesis freudiana sobre el sueño como realización vicaria de un deseo originario. (...) Si el movimiento del sueño nunca puede agotarse en el restablecimiento de una escena o un trauma originarios, esto es porque se remonta mucho más allá de ellos, para retomar los 'movimientos primeros de libertad' hasta coincidir con la 'trayectoria de la existencia misma'. Para el sujeto, seguir esta trayectoria en el sueño significa ponerse radicalmente en cuestión, arriesgarse ante todo en su propia irrealización. Lejos de reconstruir un estado arcaico precedente, un fantasma y una historia familiar, el sueño comienza destruyendo y fragmentando todo mundo real, arrastrándose ante todo a sí mismo en esta destrucción; si se retrotrae en el tiempo, es para saltar por sobre el universo objetivo y el subjetivo que le corresponde hacia 'el mundo en el alba de su primera explosión, cuando coincide todavía con su propia existencia’. Y así, como en el libro de 1969, la arqueología se definirá justamente a través de su capacidad para captar los fenómenos al nivel de su emergencia y de su puro ser ahí, así en el sueño 'se efectúa el pasaje de la antropología a la ontología', donde 'la existencia misma, en la dirección fundamental de lo imaginario, indica su propio fundamento ontológico» (Agamben, 2009: 142-144). 
La cita a la que se refiere Binswanger es la siguiente: «Digamos, en forma provisoria, y reservándonos el derecho a toda revisión eventual, que el ser hombre (Menschsein) no es, después de todo, sino el contenido efectivo y concreto de lo que la ontología analiza como la estructura trascendental del Dasein, de la presencia en el mundo» (Foucault, 1994a: 66). Binswanger pone en cuestión la prioridad que Foucault le otorga a este «contenido efectivo y concreto» del ser-en-el-mundo, es decir, su factididad. La facticidad remite al concepto heideggeriano de «estar lanzado» al mundo (Geworfenheit), el hecho mismo de existir; este es justamente el horizonte dentro del cual la psiquiatría, según Binswanger, podría explicitar dimensiones como el organismo, la corporeidad, el clima o el condicionamiento genético así como también nuestros «humores»o «estados de ánimo» (Stimmungen) y con ellos todas las dimensiones de la locura. No se trata de aplicar conceptos filosóficos a la investigación empírica, sino de mostrar cómo las construcciones científicas de la realidad tienen un carácter provisorio, de tal modo que el análisis científico de una «facticidad» concreta, visto con un trasfondo filosófico, no queda separado de las otras dimensiones del existir humano como son las de «proyecto existencial» (Entwurf), la «caída» (Verfallen), etc. Sin embargo, nótese que, a pesar de esta observación, Foucault no modifica su posición en la publicación de la IB.

Esta diferencia con Binswanger ya se encuentra en uno de los cursos que Foucault dictó en Lille: «Binswanger y la fenomenología», en 1952. A la luz de este manuscrito podemos, a nuestro juicio, comprender mejor la introducción de 1954, especialmente en lo concerniente al Daseinsanalyse. Foucault parte de un examen crítico del psicoanálisis para abordar el problema de la génesis de las significaciones en el contexto de la psicología fenomenológica de Husserl, y finalmente pasa a la presentación del proyecto de Binswanger, centrándose en la cuestión del rol de la ontología del Daseinsanalyse. Hay que remarcar que, en este texto, Foucault presenta el pensamiento de Binswanger por medio de un doble aspecto. Por un lado, y luego de haber expuesto el funcionamiento del Daseinsanalyse a través de la presentación de varios análisis clínicos, muestra que en esta psiquiatría hay una concepción heideggeriana de la existencia, aquella que «no tiene como resultado exiliar al hombre en el universo etéreo de la reflexión metafísica, sino de recuperar una reflexión sobre el hombre al nivel de su fundamento, que es el hombre en sí mismo tomado en su existencia». Y precisa: 
«El modo de interrogación de la psicopatología existencial no es una ontología, en tanto que ella es una reflexión sobre el hombre enfermo, y no puede nunca concernir más que a los modos del ser del hombre, y no a una forma general sobre el ser en tanto que realidad humana. (...) La reflexión ontológica a la manera de Heidegger no puede jamás ser referencial. No hay duda de que Binswanger lo ha querido marcar en su obra sobre la Ideenflucht, destacando la necesidad de analizar las estructuras fundamentales de la existencia humana...» (Basso, 2015: 155-156).

Según Foucault, allí donde Heidegger había indicado al «cuidado» (Sorge) como la raíz ontológica a partir de la que había que comprender la estructura práctica del Dasein, Binswanger «compromete la reflexión sobre el hombre en un impase metafísico» (Basso, 2015: 157). A diferencia de la perspectiva existencial práctica de los análisis binswangerianos, el acento puesto por el psiquiatra suizo en la unión con la comunidad y en la totalidad de las esferas del ser (la comprensión unitaria que se hacía presente en «Traum und Existenz») obliga al Daseinsanalyse a una elección:

«debe elegir, en efecto, entre un retorno al problema de la expresión, al análisis del lenguaje, a una investigación del ámbito objetivo donde el sentido adquiere esa solidez compacta que permite la comprensión y el reconocimiento; y un recurso a la metafísica del tema clásico del amor, como posibilidad fundamental de establecer entre las existencias una relación que se arraiga en ellas, pero que al mismo tiempo las excede. Dicho de otra forma, para el Daseinsanalyse, se trata de elegir entre la historia y la eternidad, entre la comunicación concreta de los hombres, y las comunión metafísica de las existencias; entre la inmanencia y la trascendencia; entre una filosofía del amor, y un análisis de la expresión, entre la especulación metafísica y la reflexión objetiva». (Ibid).

Así pues, para Foucault, ni el Daseinsanalyse ni la psicología comprensiva son capaces de afrontar de manera satisfactoria el problema antropológico de la relación entre el hombre y la enfermedad. También, como hemos visto, Foucault efectivamente opta por desarrollar un análisis de la expresión. Tal vez eso lleva a que la $I B$ derive en el esbozo de una antropología de la imaginación, que si bien apela a una noción de existencia auténtica y de libertad, ella siempre se expresa en un contenido concreto e histórico a ser develado.

\section{CONCLUSión}

En este artículo se ha intentado analizar el uso que Foucault realiza de la antropología existencial planteada por Binswanger en «Traum und Existenz». Intentamos demostrar cómo en la IB, a través del análisis del fenómeno del sueño, y de unas series de críticas a la concepción freudiana del 
sueño y husserliana del signo y la expresión, Foucault pone el acento en el fundamento ontológico de la existencia, pues ella es el fundamento del sueño. A partir de este punto, se define la orientación concreta de las formas fundamentales de la existencia. Foucault realiza un análisis de las formas de expresión a través de las cuales diversas dimensiones de la existencia aparecen en el sueño y se concretizan a través de su expresión, es decir, de su facticidad. Finalmente, este análisis del movimiento de la existencia a lo concreto lleva a Foucault a esbozar una antropología de la imaginación, que luego de criticar las versiones sartreanas y bachelardianas de la imagen, define a la imaginación como un proceso basado en la libertad dirigida hacia lo concreto, es decir, hacia una comunidad, encarnando así una tarea ética y una necesidad histórica. A partir de ello, quisimos demostrar que si bien el fundamento de Foucault, al igual que en «Traum und Existenz», esta puesto en la instancia determinante de la existencia, se plantea una diferencia importante entre ambos enfoques teóricos. Mientras que Binswanger pone el acento en una noción de individuo que supedita su existencia individual a un ideal de totalidad comunitaria (el logos heraclíteo), para Foucault la instancia determinante será la libertad, a partir de la cual la existencia puede definirse como inauténtica o como auténtica. La existencia inauténtica deriva en la patología mental, a través de una negación de la libertad fundante de la existencia, mientras que la existencia auténtica es la que intenta encarnarse a través de la tarea de dirigirse y expresarse en el lenguaje (como vimos, Foucault pone el acento en la figura del poeta, que encarnaría esta existencia auténtica); sin embargo, este esbozo de una antropología de la imaginación destaca la necesidad de dirigir la dimensión fundante de la libertad hacia sus formas de expresión concretas, lo que llevará al filósofo francés a poner el acento en la facticidad.

En lo que respecta a la fenomenología en la obra posterior de Foucault, ésta continuará siendo un objeto de interlocución, principalmente hasta Les mots et les choses. El único texto donde Foucault toma una postura explícitamente existencialista y fenomenológica, como ya mencionamos, es la IB. El desarrollo de la arqueología, durante la década del sesenta, puede ser considerado un diálogo con la fenomenología, pero en la medida en que busca separarse de ella. Por ejemplo, en La Naissance de la clinique (1963), Foucault afirma: «Las fenomenologías acéfalas de la comprensión mezclan en esta idea al ligada [se refiere a la idea del humanismo médico] la arena de 
su propio desierto conceptual» (Foucault, 1966: 8). Esto no impide que, a pesar de ello, en dicho libro se encuentren referencias (y también discusiones) implícitas con, por ejemplo, Merleau-Ponty. Sin embargo, sí marca el punto central de la interlocución con la fenomenología durante la década del sesenta: el proyecto arqueológico intenta liberar el análisis histórico de la fenomenología, es decir, de la búsqueda de un origen entendido como búsqueda de los actos fundadores. Por otra parte, Les mots et les choses es una descripción del conocimiento que se opone a la concepción husserliana de la historicidad del saber. Allí, Foucault no busca los actos fundadores de la racionalidad ni considera que la historia del conocimiento sea el desarrollo continuo y progresivo de una racionalidad, sino al contrario, considera a la historia como discontinua. De hecho, las diversas figuras de la analítica de la finitud pueden ser leídas como las dificultades o ambivalencias de las diferentes figuras de la fenomenología: el análisis de las vivencias (Merleau-Ponty), el cogito y lo impensado (Husserl), el retroceso y el retorno del origen (Heidegger) (Cfr. Castro, 2018).

Finalmente, quisiéramos realizar un último señalamiento. Por una parte, ya en este primer texto Foucault desarrolla una serie de críticas a la psiquiatría, a la psicología naturalista y al psicoanálisis que se desarrollarán en sus otros textos anteriores a Histoire de la folie à l'âge classique (su primer libro, publicado también en 1954, Maladie mentale et personnalité; y los artículos de 1957 «La psychologie de 1850 à 1950»y «La recherche scientifique et la psychologie»). Lo central de estas críticas a las ciencias psi ya se encuentra aquí en la IB: el concepto de hombre que la psiquiatría posee (un bomo natura) lo reduce a ser un objeto natural; por consecuencia, el concepto de enfermedad también será reducido a una serie de manifestaciones de causas naturales u orgánicas. La grilla existencial a través de la cual Foucault lee a la enfermedad mental en la IB (ligada a un fundamento anclado en una existencia que se vive de modo inauténtico) no será retomada, pero el fundamento existencial que subyace al hombre (su libertad originaria, asumida como una existencia auténtica), sí se mantendrá hasta 1957, y siempre en relación a su manifestación concreta e histórica. Tanto en la IB, como en Maladie mentale et personnalité y en «La psychologie de 1850 à 1950», la figura del hombre en términos existenciales y ligada al plano de lo concreto se mantiene. Por consecuencia, podemos afirmar que en estos textos, y sobre todo en lo que respecta a la $I B$, encontramos una categoría 
de sujeto como fundamento de la perspectiva filosófica que propone Foucault: una libertad fundante que se encuentra en tensión con su expresión concreta e histórica. Sin embargo, a pesar del evidente fundamento existencial de la $I B$, ya en este texto Foucault plantea la necesidad de analizar la facticidad de esa libertad fundamental, sus formas concretas.

REFERENCIAS BIBLIOGRÁFICAS:

Agamben, G.: Signatura rerum. Buenos Aires: Adriana Hidalgo, 2009.

Babich, B.: «A philosophical shock: Foucault reading Nietzsche, reading Heidegger» en Prado, C. G. (ed.): Foucault's Legacy. London: Continuum, 2009, pp. 19-41.

Basso, E.: «On Historicity and Transcendentality Again. Foucault's Trajectory from Existential Psychiatry to Historical Epistemology» en Foucault Studies, 14, pp. 154-178. 2012.

Basso, E.: «Phénoménologie et psychanalyse. Un débat entre Binswanger et Jaspers: 1913-1914» en Cabestan, P. \& Gens, J.-C.: La Psychopathologie générale de Karl Jaspers. 1913 - 2013. París: École Française de Daseinsanalyse, 2013, pp. 49-68.

Basso, E.: «La rêve et l'existence, histoire d'une traduction» en Bert, J.F. \& Basso, E.: Foucault à Münsterlingen. À l'origine de l'Histoire de la folie. París: Éditions de l'École des hautes études en sciences sociales, 2015, pp. 141-182.

Basso, E.: «Foucault entre psychanalyse et psychiatrie. 'Reprendre la folie au niveau de son langage» en Archives de Philosophie, 79, 2016a, pp. 27-54.

Basso, E.: «Á propos d'un cours inédit de Michel Foucault sur l'analyse existentielle de Ludwig Binswanger (Lille 1953-1954)» en Revue de synthèse, 137, 2016b, pp. 35-59.

Binswanger, L.: «De la dirección analítico-existencial de la investigación en psiquiatría» en Artículos y conferencias escogidas. Madrid: Gredos, 1973a, pp. 166-190.

Binswanger, L.: «Ensueño y existencia» en Artículos y conferencias escogidas. Madrid: Gredos, 1973b, pp. 67-88.

Binswanger, L.: «El concepto de hombre según Heráclito» en Artículos y conferencias escogidas. Madrid: Gredos, 1973c, pp. 89-116.

Castro, E.: Pensar a Foucault. Buenos Aires: Biblos, 1995.

Castro, E.: Diccionario Foucault. Buenos Aires: Siglo XXI, 2018. 
Chebili, S.: Foucault et la psychologie. París: L'Harmattan, 2005.

Descombes, V.: Le Même et l'Autre. Quarante-cinq ans de philosophie française (1933-1978). Paris: Éditions de Minuit, 1979.

Dreyfus, H. \& Rabinow, P.: Michel Foucault: más allá del estructuralismo y la hermenéutica. Nueva Visión, Buenos Aires, 2001.

Ellenberger, H.: «Introducción clínica a la fenomenología psiquiátrica y al análisis existencial» en May R. \& Ellenberger, H. (eds.): Existencia. Nueva dimensión en psiquiatría y psicología. Madrid: Gredos, 1967, pp. 123-162.

Eribon, D.: Michel Foucault. Barcelona: Anagrama, 1992.

Foucault, M.: Enfermedad mentaly personalidad. Buenos Aires: Siglo XXI, 1961.

Foucault, M.: El nacimiento de la clínica. Buenos Aires: Siglo XXI, 1966.

Foucault, M.: Las palabras y las cosas. Buenos Aires: Siglo XXI, 1968.

Foucault, M.: Histoire de la folie à l'âge classique. París: Gallimard, 1972.

Foucault, M.: «Introduction» en Dits et Écrits I. 1954-1969. Paris: Gallimard, 1994a, pp. 65-119.

Foucault, M.: «La psychologie de 1850 à 1950» en Dits et Écrits I. 19541969. Paris: Gallimard, 1994b, pp. 120-137.

Foucault, M.: «La recherché scientifique et la psychologie» en Dits et Écrits I. 1954-1969. Paris: Gallimard, 1994c, pp. 137-158.

Foucault, M.: «Préface à l'Histoire de la sexualité» en Dits et Écrits IV. 1980-1988. Paris: Gallimard, 1994d, pp. 578-584.

Foucault, M.: «Cómo nace un libro-experiencia» en Trombadori, D.: Conversaciones con Foucault. Buenos Aires: Amorrortu, 2010.

Geroulanos, S.: An atheism that is not humanist emerges in French thought. California: Standford University Press, 2010.

Gros, F. Foucaulty la locura. Buenos Aires: Nueva Visión, 2000.

Hall, C. \& Gardner, L.: La teoría existencialista de la personalidad. Binswanger y Boss. Buenos Aires: Paidos, 1977.

Janicaud, D.: Heidegger en France. París: Albin Michel, 2001.

Kleinberg, E.: Generation Existential. Heidegger's Philosophy in France 19271961. Ithaca y Londres: Cornell University Press, 2005.

Kripper, A.: «Foucault y la expresión» en .Kripper, A. y Lutereau, L. (comps): Deseo, poder y diferencia. Foucaulty el psicoanálisis. Buenos Aires: Letra Viva, 2013, pp. 117-134.

Lanzoni, S.: «An epistemology of the Clinic: Ludwig Binswanger's Phe- 
nomenology of the Other» en Critical Inquiry, Vol. 30, 1, 2003, pp. 160-186.

Lebrun, G. «Nota sobre la fenomenología contenida en Las palabras y las cosas» en AA.VV:: Michel Foucault, filósofo. Barcelona: Gedisa, 1990, pp. 31-47.

Marazia, C.: «Ludwig Binswanger y el ritual de la salvación» en Binswanger, L. \& Warburg, A.: La curación infinita. Historia clínica de Aby Warburg. Buenos Aires: Adriana Hidalgo, 2007, pp. 265-278.

May, T.: «Foucault's Relation to Phenomenology» en Gutting, G. (comp.): The Cambridge Companion to Foucault. New York: Cambridge University Press, 2005, pp. $284-311$.

Micieli, C.: Foucaulty la fenomenología. Kant, Husserl, Merleau-Ponty. Buenos Aires: Biblos, 2003.

Milchman, A. \& Rosenberg, A.: Foucault and Heidegger Critical Encounters Contradictions of Modernity. Minneapolis: University of Minessota Press, 2003.

Miller, J.: La pasión de Michel Foucault. Santiago de Chile: Andes Bello, 1995.

Moreno Pestaña, J. L.: Convirtiéndose en Foucault. Sociogénesis de un filósofo. Madrid: Montesinos, 2006.

Morey, M.: Lectura de Foucault. Madrid: Taurus, 1983.

Pettigrew, D. \& Raffoul, F.: French interpretations of Heidegger. New York: State University of New York Press, 2008.

Rayner, T.: «Foucault, Heidegger and the History of Truth» en O'Leary, T. \& Falzon, C. (dirs.): Foucault and philosophy. Oxford: Wiley-Blackwell, 2010, pp. 60-77.

Revel, J.: «Sur l'introduction à Binswanger (1954)» en Giard, L. (dir.): Michel Foucault. Lire l'œuvre. Grenoble: Jérôme Millon, 1992.

Rockmore, T.: Heidegger and french philosophy. Londres y New York, 1995.

Sabot, P.: «Entre psychologie et philosophie. Foucault à Lille, 19521955» en Bert, J.-F. \& Basso, E. Foucault à Münsterlingen. À l'origine de l'Histoire de la folie. París: Éditions de l'École des hautes études, 2015, pp. 103-126.

Seitter, W.: «Onirocríticas» en VV. AA. Michel Foucault, filósofo. Barcelona: Gedisa. 1990, pp.140-144.

Sheridan, A.: Michel Foucault: The Will to Truth. London: Tavistock, 1980. Smyth, B.: «Foucault and Binswanger. Beyond the dream» en Philosophy 
Today, 55, 2011, pp. 92-101.

Spiegelberg, H.: Phenomenology in Psychology and Psychiatry. A Historical Introduction. Evanston: Northwestern University Press, 1972.

Visker, R.: Truth and singularity: taking Foucault into phenomenology. Dordrecht, Boston, Londres: Springer, 1999.

Waldenfels, B.: De Husserl a Derrida. Introducción a la fenomenología. Barcelona: Paidos, 1997.

Zougrana, J.: Michel Foucault, un parcours croisé: Lévi-Strauss, Heidegger. París: L’Harmattan, 1998.

Matias Abeijon es becario de investigación en la Universidad de Buenos Aires.

Lineas de investigación:

Historia de la Psicología, Psicoanálisis, Foucault, Epistemología Francesa.

Publicaciones recientes:

- «Experiencia, tragedia y transgresión en Michel Foucault y Georges Bataille». Factótum. Revista de filosofía, n. ${ }^{\circ} 19$ (2018), 109-120.

- «Michel Foucault y la estructura trágica. Una temprana lectura nietzscheana de la tragedia», Areté: Revista de filosofía, Vol. 30, n. ${ }^{\circ}$ (2018), 101-123.

Dirección electrónica: matiasabeijon@gmail.com 